\title{
Nano-engineered Composites: Interlayer Carbon Nanotubes Effect
}

\author{
Glaucio Carley", Viviany Geraldo ${ }^{\mathrm{b}}$, Sergio de Oliveira ${ }^{\mathrm{b}}$, Antonio Ferreira Avila ${ }^{\mathrm{c}}$ \\ ${ }^{a}$ Mechanical Engineering Graduate Studies Program, Universidade Federal de Minas Gerais - UFMG, \\ Av. Antonio Carlos, 6627, CEP 31270-901, Belo Horizonte, MG, Brazil \\ ${ }^{\mathrm{b}}$ Physics Department, Universidade Federal de Minas Gerais - UFMG, Av. Antonio Carlos, 6627, \\ CEP 31270-901, Belo Horizonte, Brazil \\ ${ }^{\mathrm{c}}$ Mechanical Engineering Department, Universidade Federal de Minas Gerais - UFMG, \\ Av. Antonio Carlos, 6627, CEP 31270-901, Belo Horizonte, Brazil
}

Received: November 3, 2012; Revised: December 19, 2012

\begin{abstract}
The concept of carbon nanotube interlayer was successfully introduced to carbon fiber/epoxy composites. This new hybrid laminated composites was characterized by Raman spectroscopy, X-ray diffraction, scanning electron microscopy and tensile tests. An increase on peak stress close to $85 \%$ was witnessed when CNTs interlayer with $206.30 \mathrm{mg}$ was placed to carbon fiber/epoxy laminates. The failure mechanisms are associated to CNTs distribution between and around carbon fibers. These CNTs are also responsible for crack bridging formation and the increase on peak stress. Initial stiffness is strongly affected by the CNT interlayer, however, changes on stiffness is associated to changes on nano/micro-structure due to damage. Three different behaviors can be described, i.e. for interlayers with $\approx 60 \mathrm{mg}$ of CNT the failure mode is based on cracks between and around carbon fibers, while for interlayers with CNT contents between $136 \mathrm{mg}$ and $185 \mathrm{mg}$ cracks were spotted on fibers and inside the CNT/matrix mix. Finally, the third failure mechanism is based on carbon fiber breakage, as a strong interface between CNT/matrix mix and carbon fibers is observed.
\end{abstract}

Keywords: carbon nanotubes, carbon fiber/epoxy composites, interlayers, raman spectroscopy

\section{Introduction}

As described by Saito et al. ${ }^{1}$, carbon nanotube is a honeycomb lattice rolled into a cylinder. Carbon nanotubes (CNTs) have been the center of many researches due to their dimensions and remarkable electro-mechanical properties. In general, a CNT diameter has a nanometer size and its length can be more than $1 \mu \mathrm{m}$. Its large aspect ratio (length/diameter) is appointed as one of the reasons for the CNTs notable properties. According to Kalamkarov et al. ${ }^{2}$, single-walled nanotubes (SWNTs) have predicted specific strength around 600 times larger than steel. CNT capabilities have been observed experimentally and verified by numerical simulations. Frankland et al. ${ }^{3}$, Jin and Yuan ${ }^{4}$ and Agrawal et al. ${ }^{5}$ are among those researchers who employed molecular dynamics for analyzing CNTs. The atomistic simulation approach was employed by Belytschko et al. ${ }^{6}$, Lurie et al. ${ }^{7}$, Gates et al. ${ }^{8}$, while the nano-mechanics modeling was described by Liu et al. ${ }^{9}$, Ruoff and Pugno ${ }^{10}, \mathrm{Li}$ and $\mathrm{Chou}^{11}$, Ávila et al. ${ }^{12}$. Although CNTs have tremendous potential in a large variety of applications, e.g. aerospace and medical industries, there is no consensus about their exact mechanical properties. The experiments performed up to now have presented large variability due to the inherent complexity of manipulating these materials. However, their potential is unquestionable, in special for composites.

As mentioned by Ávila et al. ${ }^{13}$, carbon based nano-structures, i.e. carbon nanotubes and graphene nano sheets (GN), can be combined to traditional composites for a multi-scale reinforcement. Moreover, with the recent developments on CNT synthesis, its price per gram has dramatically reduced. As a consequence, the number of

*e-mail: carleyone@hotmail.com researchers using carbon based nanostructures increased, and the results on nano-reinforcement of composites laminates are encouraging. Among those researchers are Kim and collaborators ${ }^{14}$ whom described no significant increase on tensile properties of the addition of CNTs to carbon fibers/epoxy laminates. Nonetheless, they noticed an enhancement on flexural modulus $(\approx 12 \%)$ and strength $(\approx 18 \%$ ) with the addition of 0.3 wt. $(\%)$ of CNT to the epoxy system. This increase can be attributed to changes into flexural failure mechanisms. Following the same idea, Chou et al. ${ }^{15}$ discussed the influence of CNTs into the failure of laminated composites. They even proposed the concept of a hybrid inter-laminar architecture that can bridge interlaminar cracks. Wicks and colleagues ${ }^{16}$ actually produced the hybrid nano reinforced laminated composites proposed by Chou et al. ${ }^{15}$ In their laminate, CNTs were grown in situ in all fibers leading to a "fuzzy" fibers configuration. As mentioned by Wicks, aligned CNTs bridges the plies interfaces, which can lead to an increase on toughness, for the steady state condition, $76 \%$ higher than the conventional laminated systems. Notice that for the interlayer nano reinforcement some issues must be considered, i.e. the interfacial bonds between carbon nanotubes and the fiber/ matrix system and the length effect into this "grip condition". To understand the failure mechanism, Shokrieh and Rafiee ${ }^{17}$ modeled the CNT length effect on reinforcement effectiveness. Moreover, they concluded that for carbon nanotubes with length less than $100 \mathrm{~nm}$, the improvement on stiffness for CNT/polymeric systems is negligible. By taking into consideration Shokrieh and Rafiee ${ }^{17}$ conclusions and the work done by Ma et al. ${ }^{18}$ for dispersing carbon nanotubes 
into polymeric matrices, it is clear that although CNTs are a viable option for reinforcement of nanocomposites and its hybrid companions. However, the idea of dispersing nanotubes into polymeric matrices as described by Shokrieh and Rafiee $^{17}$ and $\mathrm{Ma}$ et al. ${ }^{18}$ seems to be limited. The "fuzzy" fibers configuration developed by Wicks et al. ${ }^{16}$ is also limited as all plies have to be loaded with carbon nanotubes. This increase on "fiber density" due to the "CNTs loads" can lead to difficulties for using the vacuum assisted impregnation system, as resin flow channels will be reduced. It is clear that alternative techniques must be developed.

Different techniques have being tested for incorporating CNTs into composite materials. The CNT infusion into laminated composites and its alignment by applying an electric field after the infusion was studied by Domingues et al. ${ }^{19}$. The major criticism about Domingues' work is the amount of CNT dispersed which is around $0.1 \mathrm{wt}$. (\%). Another approach tried to link CNTs to laminated composites was implemented by Wu et $\mathrm{al}^{20}$. Wu's work was based on electrochemical grafting of CNTs on carbon fibers surface. Although the technique described by Wu et al. ${ }^{20}$ seems to be effective, it is limited to the CNT concentration into the solution. Moreover, as noticed by $\mathrm{Wu}$, there were "preferential regions" for CNTs direct attachment to carbon fibers. These preferred sites were fibers' grooves and edges. This phenomenon led to a non-uniform distribution of CNT on carbon fibers surface. Another technique used for attaching CNTs to carbon fibers was studied by De Riccardis et al..$^{21}$ and Vilatela et al. ${ }^{22}$. In their case, the chemical vapor deposition (CVD) technique was employed for directly grown CNTs into carbon fibers. De Riccardis' work was based on deposition of nickel clusters and later on the CNTs were grown by hot filament chemical vapor deposition (HFCVD) technique. By using ferrocene as precursor, and CVD as the growing process, Vilatela was also able to obtain good quality CNTs. Moreover, the CVD technique employed by Vilatela et al. ${ }^{22}$ seems to be much simpler and easier to control. Although the results presented by De Riccardis et $\mathrm{al}^{21}$ and Vilatela et al..$^{22}$ seems to be encouraging much work has to be done for applications to laminated composites, in special high performance carbon fiber/epoxy systems.

As commented by Khan and $\mathrm{Kim}^{23}$, the incorporation of nanoscale CNTs with conventional micro scale fiber reinforcement in polymeric composites can be obtained by modifying either the matrix or the fibers. Qian et al. ${ }^{24}$ mentioned that the most common manufacturing process for hybrid composites (composites with at least two levels of reinforcement, at micro and nano-scale) is based on shear mixing the CNTs into the resin system, followed by infusion/impregnation and consolidation processes. This entire manufacturing procedure is limited by the CNTs loadings due to the matrix viscosity increase. Karapappas et al. ${ }^{25}$ employed a torous mill device for dispersing CNTs into an epoxy system, a later on the hand layup process was applied followed by an autoclave consolidation. For Mode I fracture toughness, the results were consistent, in other words, an increase on CNT levels will lead to a correspondent increase on Mode I fracture toughness. For Mode II, however, a different scenario was noticed. The intermediate concentration (0.5 wt. (\%)) got the highest value. This could indicate some problems during the dispersion process and at interface nano-modified matrix/fibers. To try to overcome this problem Seyhan et al. ${ }^{26}$ used the three-roll mill. Although the dispersion quality was improved, the matters of CNTs loadings remained. They were able to disperse only $0.1 \mathrm{wt}$. (\%) of CNTs.

Khan and $\mathrm{Kim}^{23}$, however, discussed alternative techniques such as, direct CNTs in situ growth, manual spreading or spraying the CNTs among others. The work reported by Garcia et al. ${ }^{27}$ can be described as the in situ CNTs growth process. In this case, they employed alumina fibers and hand layup process. They reported an increase on interlaminar shear strength (ILSS), close to $69 \%$ with small standard deviation.

The work done by Arai et al. ${ }^{28}$ fits on second category, as they dispersed a CNT powder using a sifter into carbon/epoxy prepregs. They discussed the influence of the testing method into the interlaminar shear strength. A similar approach, the sifter usage into nano/micro structures (in this case vapor grown carbon fibers - VGCF) was employed by $\mathrm{Li}$ et al. ${ }^{29}$. Based on mode I fracture toughness results presented by Li et al., it seems that an saturation limit on VGCF is around g. $\mathrm{m}^{-2}$. Moreover, the zigzag fracture pattern could be the reason for the increase on fracture toughness, as the energy release rate is higher. The work done by Joshi and Dikshit ${ }^{30}$ followed the idea of dispersing/transfer CNTs into prepreg surfaces. They sprayed an ethanol/CNT solution into a peel cloth and then the CNTs were mechanically transferred to the prepregs by applying a pressure. This procedure has two major problems: first ethanol is harmful for prepregs and the second problem is that by spraying the solution into the cloth and later transferring to the prepregs, there is always the possibility of agglomeration and non-uniform CNT distribution. This seems the case for high CNTs concentrations $\left(2.25\right.$ g. $\mathrm{m}^{-2}$ and $\left.3.62 \mathrm{~g} . \mathrm{m}^{-2}\right)$ employed by Joshi and Dikshit ${ }^{30}$. To avoid the problem of prepregs degradation by ethanol, Davis and Whean ${ }^{31}$, used not impregnated carbon fibers. The amount of CNTs employed was 0.3 wt. (\%) and 0.5 wt. (\%), a very small percentage. After spraying the ethanol/CNT solution into the fibers, they allowed the ethanol evaporation, and later employed the heated vacuum resin transfer molding process (HVRTM). Although they reported an increase on failure initiation close to $23 \%$, their standard deviation indicates problems into the CNTs homogeneity. The resin flow during the HVRTM could simply wash out the CNTs in different regions of the composite panel. A more efficient way to transfer CNTs to prepregs and/or not impregnated fibers was described by Garcia et al. ${ }^{32}$. In their case, they did an in situ CNT growth in a Si substrate, and the transfer were performed by rolling the prepregs into a cylinder and then the cylinder was rolled over the Si substrate while applying a small pressure. They reported an increase on energy release rate in Mode II close to $300 \%$ with small standard deviation.

This paper discusses the advantages and disadvantages of CNTs in situ growth into not impregnated carbon fibers where the CNT forest is partially filled by the net resin during the impregnation process. Differently from the work done by Garcia et al. ${ }^{32}$ where the CNT forest was completely filled with resin, in this paper the CNT forest was partially filled by the net resin. By employing this strategy, the bridging condition is explicitly imposed.

\section{Material and Methods}

As discussed by Mathur et al. ${ }^{33}$, thermal CVD has high growth rate, i.e. $10 \mu \mathrm{m} / \mathrm{min}$, and the CNTs diameters ranges 
from $\approx 40-60 \mathrm{~nm}$. Moreover, Raman spectroscopy indicates a good crystallinity of multiwall carbon nanotubes (CTN's). In this research, a thermal CVD device from FirstNano was used for growing CNTs directly into glass fibers. CNTs can be grown over a temperature range of $600-900{ }^{\circ} \mathrm{C}$ using thermal CVD. After a series of tests, the optimum temperature, considering the CNTs alignment, was selected as $750{ }^{\circ} \mathrm{C}$ at an inert atmosphere (argon). The precursor employed was a mix of ferrocene and toluene $(2 \%)$. The precursor was evenly distributed into the fibers' cloth, and later on the fibers' cloth with the precursor was place in the furnace main heating zone. The temperature gradient from the furnace center to the edge was $\approx 10^{\circ} \mathrm{C} . \mathrm{cm}^{-1}$, at a nominal temperature of $750{ }^{\circ} \mathrm{C}$. The CNTs grown for this research were mainly Multiwall Carbon Nanotubes (MWNT).

The plain weave fiber glass used in this research has an areal density of $180 \mathrm{~g} . \mathrm{m}^{-2}$. To be able to understand the carbon nanotubes effect as interlayer into carbon/epoxy laminated composites, five different CNTs forests were grown in situ into the plain weave fiber glass. These fiber glass fabrics loaded with CNTs were placed between two layers of carbon fibers. The carbon fibers have a plain weave configuration and areal density of $200 \mathrm{~g} / \mathrm{m}^{2}$. The epoxy system employed here is based on diglycidil ether bisphenol $A$ (DGBA) resin and an amine hardener, i.e. AR300 and a mix of AH300/AH150 supplied by Barracuda Composites Inc. The resin/hardener ratio employed was 100:27. The fiber/epoxy system ratio is equal to 50:50. The resin impregnation is based on hand lay-up while the composite final consolidation is performed by cure under vacuum. The total time for cure was 24 hours, 6 under vacuum and the remaining under air.

According to Koo et al. ${ }^{34}$, during the nanoparticles dispersion into polymeric matrices nano-structures are formed. The two most common detection techniques to nano-structures identification are X-ray diffraction and electron microscopy. In this research, X-ray diffraction (XRD) experiments were carried out on a Shimadzu XRD-6000 X-ray diffract meter with $\mathrm{Cu}(\lambda=0.154 \mathrm{~nm})$ irradiation at $40 \mathrm{kV}$ and $30 \mathrm{~mA}$ using a Ni filter. Data were recorded in the range from 2 to $80 \mathrm{deg}$ in a continuous scanning at 2 degrees per minute and sampling pitch of 0.02 deg.. The high resolution scanning electron microscope (HRSEM) used was a Quanta 200 - FEG - FEI, while the transmission electron microscope (TEM) employed was a

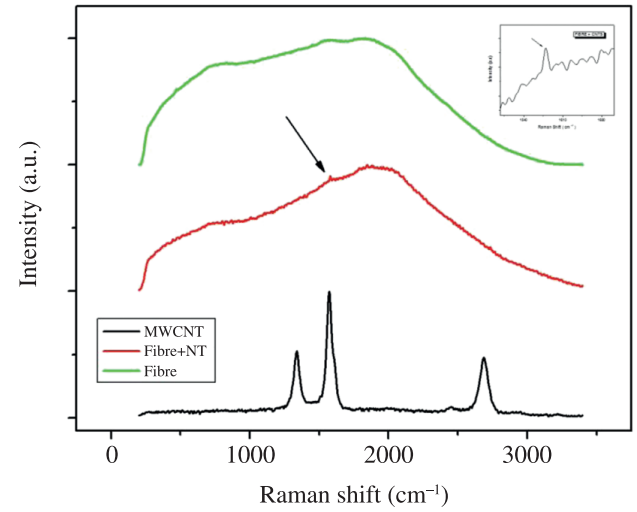

(a)
Tecnai-G2-20-FEI. As mentioned by Dresselhaus et al. ${ }^{35}$, Raman spectroscopy is also a powerful tool for studying carbon based nanostructures, i.e. CNTs and graphene nanosheets. In this study, the Raman spectroscopy analysis was performed using a DilorXY 800 Raman spectrograph.

DilorXY 800 Raman spectrograph has an $800 \mathrm{~mm}$ focal length triple spectrograph, f/6 subtractive or additive fore-monochromator - Gratings $1200 \mathrm{~g} \cdot \mathrm{mm}^{-1}$, spectral range $27,000 \mathrm{~cm}^{-1}$ to $5 \mathrm{~cm}^{-1}$, and it is equipped with a 2 watts argon laser with wavelength of $514.5 \mathrm{~nm}$ or $488 \mathrm{~nm}$, a $10 \mathrm{nW}$ $\mathrm{HeNe}$ laser with wavelength of $632.8 \mathrm{~nm}$. The scanning is performed by a motorized xy stage for confocal microscope with $0.1 \mu \mathrm{m}$ resolution and software for Raman map.

The hybrid laminated composite mechanical characterization is based on tensile tests following ASTM D 3039 standard $^{36}$. An EMIC DL-10000 universal testing machine with $10 \mathrm{KN}$ and a $500 \mathrm{~N}$ load cells was used to perform the tensile tests at constant displacement of $0.5 \mathrm{~mm} / \mathrm{min}$. Load and displacement were continually measured by the load cell and extensometer, respectively. Furthermore, as this research focuses on understanding the CNT inter-lamina effect into laminated composites, the concept of representative volume element (RVE) described by Ávila et al. ${ }^{12}$ was employed. The hybrid composite laminate was composed of two layers of carbon fiber/epoxy with an extra inter-layer of fiber glass fabric where CNTs were grown in situ by thermal CVD. The total average thickness was around $0.145 \mathrm{~mm}$. The other dimensions followed the ASTM D 3039 standard. By applying the RVE concept, it was possible to obtain a direct relation between the CNTs effects into the composite's macroscopic behavior.

\section{Data Analysis}

As this research deals with multi-scale composite reinforcement, i.e. from nano to macro, two different approaches are employed. The first one is related to nano and micro structure analysis based on HSEM, Raman spectroscopy and X-ray diffraction analysis. The second one is based to tensile tests and failure mode analysis. By analyzing the two sets of data, it is possible to correlate the nano/micro structure formed and the hybrid composite macroscopic behavior.

Figures 1a, b show the Raman spectroscopy and the $\mathrm{X}$-ray diffraction signatures for the hybrid laminated

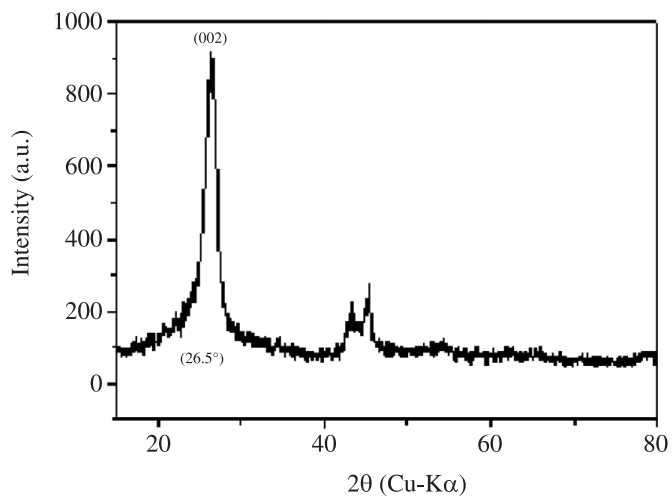

(b)

Figure 1. Fiber and CNTs characterization. (a) Raman spectroscopy; (b) CNTs' XRD signature. 


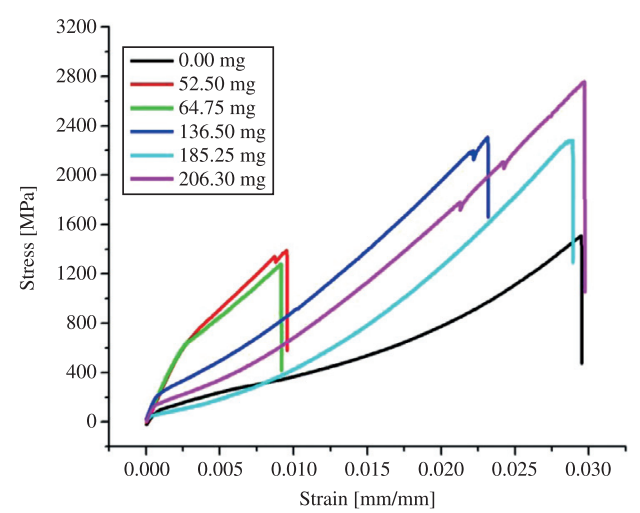

(a)

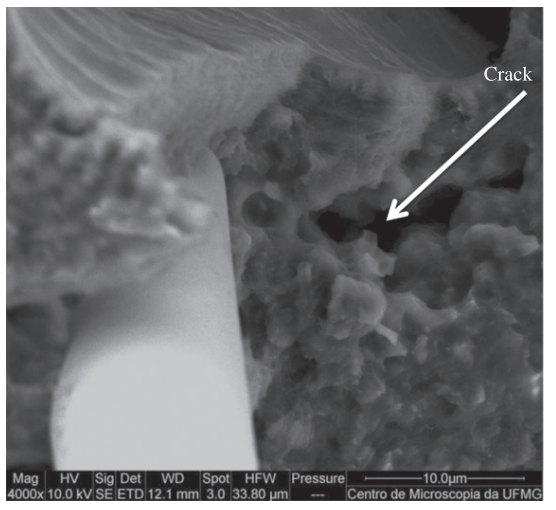

(b)

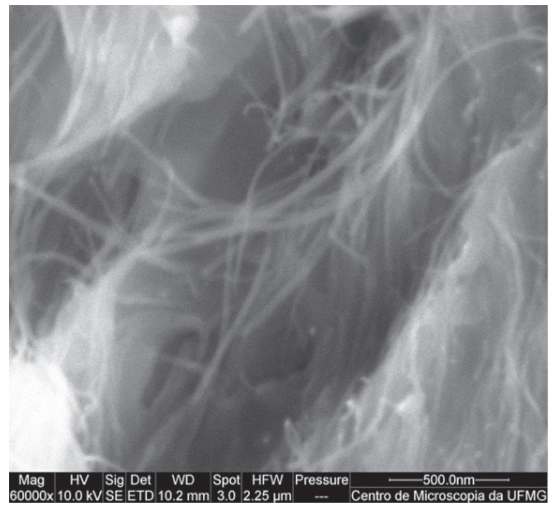

(d)

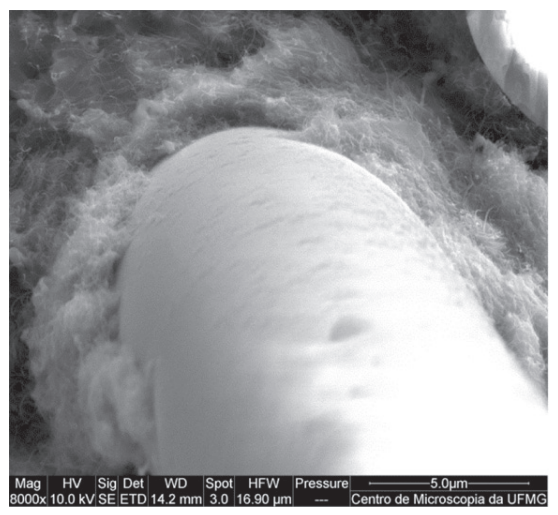

(f)

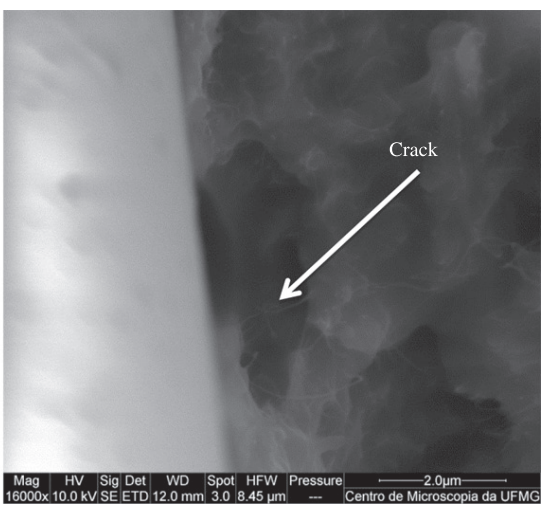

(c)

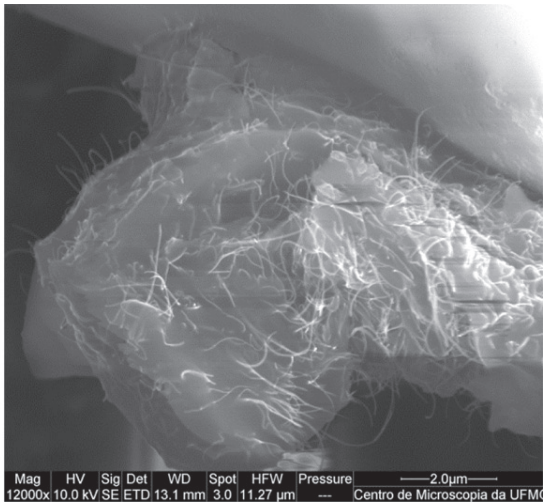

(e)

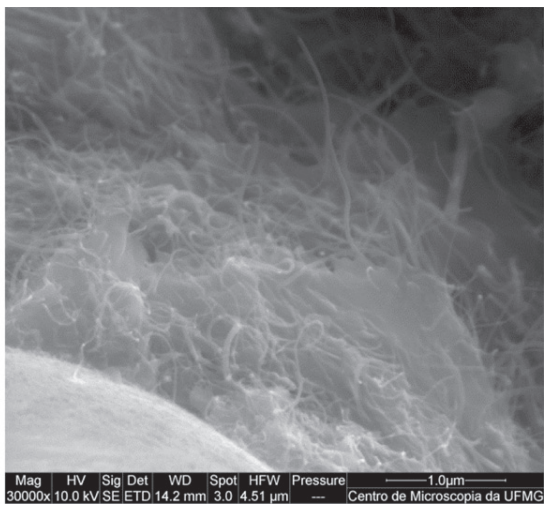

(g)

Figure 2. Hybrid laminated composite with CNT inter-layer. (a) Stress-strain curves; (b) Fiber/CNTs for $52.50 \mathrm{mg}$; (c) Fiber/CNTs for $64.75 .50 \mathrm{mg}$; (d-e) Fiber/CNTs for $136.50 \mathrm{mg}$; (f) Fiber/CNTs for $185.25 \mathrm{mg}$; (g) Fiber/CNTs for $206.30 \mathrm{mg}$. 
composite with CNTs as interlayer. As it can be observed in Figure 1a, for CNTs (the lower curve), three bands can be easily identified. The D band is around $1340 \mathrm{~cm}^{-1}$, while the $\mathrm{G}$ band is located around $1580 \mathrm{~cm}^{-1}$ and the $\mathrm{G}^{\prime}$ band is nearby $2685 \mathrm{~cm}^{-1}$. As described by Malard et al. ${ }^{37}$ and Dresselhaus et al. ${ }^{35}$ these peak values are typical from carbon based materials. Furthermore, the narrow and intense $\mathrm{D}$ band could be associated to the small nanotube diameter $(\approx 20 \mathrm{~nm})$ and the high intensity can be related to CNTs length. Moreover, the narrow $\mathrm{G}$ band is related to the CNT's crystallinity, which is confirmed by the XRD signature shown in Figure 1b. By analyzing the second curve (fibers + CNTs), it is possible to observe the carbon fibers' amorphous behavior represented by the smooth curve. However, the carbon nanotubes $\mathrm{G}$ band is also observed superposed to the smooth curve. The $\mathrm{G}$ band is indicated by the arrow and a region's zoom is shown on Figure 1a upper right corner. Finally, the last curve (upper curve) indicates the fiber glass amorphous behavior.

To understand the how the interlayer nanotubes impact the laminated composites' macroscopic behavior under tension five different CNTs forests were grown into the fiber glass cloths. The amount of CNTs grown in each fiber glass interlayer can be described as $52.50 \mathrm{mg}, 64.75 \mathrm{mg}$, $136.50 \mathrm{mg}, 185.25 \mathrm{mg}$, and $206.30 \mathrm{mg}$, respectively.

Figure 2 a shows the stress-strain curves for the hybrid laminated composite. As it can be noticed as we are dealing with a $R V E$ (a thin laminate), the stresses are "naturally" high. Moreover, changes on peak stress and stiffness are observed. The peak stress changes seem to be attributed to the failure modes. As it can be noticed in Figure $2 \mathrm{~b}$ cracks between fibers and also around fibers were observed. CNTs, however, are everywhere and this distribution lead to bridges between cracks (see CNTs at Figure 2c) and consequently and increase on peak stress. As the failure mechanism is the same for both cases, the peak stress for CNTs concentrations of 52.50 and $64.75 \mathrm{mg}$ are statistically similar. An increase on CNTs concentration to $136.50 \mathrm{mg}$ and $185.25 \mathrm{mg}$ lead to another level of peak stress, i.e. from $\approx 1350 \mathrm{MPa}$ to $\approx 2300 \mathrm{MPa}$. Again the failure mechanism seems to the same for both cases ( $136.50 \mathrm{mg}$ and $185.25 \mathrm{mg}$ ). No cracks are noted between fibers, but cracks were spotted on fibers and inside the CNT/matrix mix (Figures 2d, e). Finally, as expected, the increase on CNTs concentration to $206.30 \mathrm{mg}$ leads to the highest peak stress $(\approx 2800 \mathrm{MPa})$. This

\section{References}

1. Saito R, Dresselhaus G and Dresselhaus MS. Physical Properties of Carbon Nanotubes. London: Imperial College Press; 2005. p. 1-53.

2. Kalamkarov AL, Georgiades AV, Rokkam SK, Veedu VP and Ghasemi-Nejhad MN. Analytical and numerical techniques to predict carbon nanotubes properties. International Journal of Solids and Structures. 2006; 43:6832-6854. http://dx.doi. org/10.1016/j.ijsolstr.2006.02.009

3. Frankland SJV, Harik VM, Odegard GM, Brenner DW and Gates TS. The stress-strain behavior of polymer-nanotube composites from molecular dynamics simulation. Composites Science and Technology. 2003; 63:1655-1661. http://dx.doi. org/10.1016/S0266-3538(03)00059-9 performance can be attributed to the strong bond between fibers and CNTs as it can be observed in Figures $2 \mathrm{~g}$, h.

In summary, when peak stresses are considered, it is possible to conclude that the addition of the CNT interlayer lead to an increase close to $85 \%$. However, changes on stiffness during the tensile test indicate changes on nano/micro-structures due to damage. The increase on stiffness from $33.99 \mathrm{GPa}$ (from samples with no CNTs) to $235.13 \mathrm{GPa}$ (from samples with CNT concentrations of $52.50 \mathrm{mg}$ and $64.75 \mathrm{mg}$ ) was not only due to the CNT concentration but it is also related to the CNTs distribution. As cited by Thostenson et al. ${ }^{38}$, an increase on stiffness is associated to a decrease on displacement and strain, and vice-versa (as shown in Figure 2a).

\section{Conclusions}

CNT interlayers were successfully introduced to carbon fibers/epoxy laminated composites. An increase on peak stress close to $85 \%$ was witnessed when CNTs interlayer with $206.30 \mathrm{mg}$ was placed in carbon fiber/epoxy laminates. The failure mechanisms are associated to CNTs distribution between and around carbon fibers. These CNTs are also accountable for crack bridging formation and the increase on peak stress. The initial stiffness is strongly affected by the CNT interlayer, however, changes on stiffness is related to changes on nano/micro-structure due to damage. Cracks between fibers were observed in hybrid composites with interlayers made of $52.50 \mathrm{mg}$ and $64.75 \mathrm{mg}$. When the amount of nanotubes is increased to $136.50 \mathrm{mg}$ and $185.50 \mathrm{mg}$, no cracks are noted between fibers, but cracks were spotted on fibers and inside the CNT/matrix mix. Finally, when the CNT amount reached $206.30 \mathrm{mg}$, the main failure mode was fiber breaking, as a strong bond between fiber/CNTs was observed by SEM.

\section{Acknowledgements}

This research was supported in part by the AFOSR under contract FA9550-10-1-0050, the Brazilian Research Council (CNPq) under grants number 303447/2011-7 and 472583/2011-5, and the Minas Gerais State Research Foundation (FAPEMIG) grant TEC-PPM00192-12. The authors would like to recognize the technical support provided by the Nanomaterial's Laboratory from the Physics department of Universidade Federal de Minas Gerais where the CNT were in situ grown on the surface of glass fibers.

4. Jin Y and Yuan FG. Simulation of elastic properties of single-walled carbon nanotubes. Composites Science and Technology. 2003; 63:1507-1515. http://dx.doi.org/10.1016/ S0266-3538(03)00074-5

5. Agrawal PM, Sudalayandi BS, Raff LM and Komanduri R. A comparison of different methods of Young's modulus determination for single-wall carbon nanotubes (SWCNT) using molecular dynamics (MD) simulations. Computational Materials Science. 2006; 38:271-281. http://dx.doi. org/10.1016/j.commatsci.2006.02.011

6. Belytschko T, Xiao SP, Schats GC and Ruoff RS. Atomistic simulations of nanotube fracture. Physical Review B. 2002; 65:2354301-2354308. http://dx.doi.org/10.1103/ PhysRevB.65.235430 
7. Lurie S, Belov P, Volkov-Bogorodsky D and Tuchkova N. Nanomechanical modeling of the nanostructures and dispersed composites. Computational Materials Science. 2003; 28:529-539. http://dx.doi.org/10.1016/j. commatsci.2003.08.010

8. Gates TS, Odegard GM, Frankland SJV and Clancy C. Computational materials: Multi-scale modeling and simulation of nanostructured materials. Composites Science and Technology. 2005; 65:2416-2434. http://dx.doi.org/10.1016/j. compscitech.2005.06.009

9. Liu WK, Karpov EG, Zhang S and Park HS. An introduction to computational nanomechanics and materials. Journal of Applied Mechanical Engineering. 2004; 193:1529-1578. http:// dx.doi.org/10.1016/j.cma.2003.12.008

10. Ruoff RS and Pugno N. Mechanics of nanostructures. In: Chuang TS, Anderson PM, Wu MK and Hsieh S, editors. Nanomechanics of Materials and Structures. New York: Springer; 2006. p. 199-203. PMid:16393445. http://dx.doi. org/10.1007/1-4020-3951-4_19

11. Li C and Chou T-W. A structural mechanics approach for the analysis of carbon nanotubes International Journal of Solids and Structures. 2003; 40:2487-2499. http://dx.doi.org/10.1016/ S0020-7683(03)00056-8

12. Ávila AF, Eduardo AC and Silva Neto A. Vibrational analysis of graphene based nanostructures. Computers and Structures. 2011; 89:878-892. http://dx.doi.org/10.1016/j. compstruc.2011.02.017

13. Ávila AF, Yoshida MI, Carvalho MGR, Dias EC and De Ávila Junior J. An investigation on post-fire behavior of hybrid nanocomposites under bending loads. Composites Part B. 2010; 41:380-387. http://dx.doi.org/10.1016/j. compositesb.2010.02.002

14. Kim M, Park Y-B, Okoli OI and Zhang C. Processing, characterization, and modeling of carbon nanotube-reinforced multiscale composites. Composites Science and Technology. 2009; 69:335-342. http://dx.doi.org/10.1016/j. compscitech.2008.10.019

15. Chou T-W, Gao L, Thostenson E, Zhang Z and Byun J-H. An assessment of the science and technology of carbon nanotube-based fibers and composites. Composites Science and Technology. 2010; 70:1-19. http://dx.doi.org/10.1016/j. compscitech.2009.10.004

16. Wicks SS, De Villanova RG and Wardle BL. Interlaminar and intralaminar reinforcement of composite laminates with aligned carbon nanotubes. Composites Science and Technology. 2010; 70:20-28. http://dx.doi.org/10.1016/j. compscitech.2009.09.001

17. Shokrieh MM and Rafiee R. Investigation of nanotube length effect on the reinforcement efficiency in carbon nanotube based composites. Composite Structures. 2010; 92:2415-2420. http:// dx.doi.org/10.1016/j.compstruct.2010.02.018

18. Ma P-C, Siddiqui NA, Marom G and Kim J-K. Dispersion and functionalization of carbon nanotubes for polymer-based nanocomposites: A review. Composites Part A. 2010; 41:13451367. http://dx.doi.org/10.1016/j.compositesa.2010.07.003

19. Domingues D, Logakis E and Skordos AA. The use of an electric field in the preparation of glass fibre/epoxy composites containing carbon nanotubes. Carbon. 2012; 50:2493-2503. http://dx.doi.org/10.1016/j.carbon.2012.01.072

20. Wu G-P, Wang Y-Y, Li D-H, Lu C-X, Shen W-Z, Li X-T et al. Improving the electrical conductivity of multi-walled carbon nanotube networks by $\mathrm{H}$ ion beam irradiation. Carbon. 2011; 49:2141-2161. http://dx.doi.org/10.1016/j. carbon.2010.12.067
21. De Riccardis MF, Carbone D, Makris TD, Giorgi R, Lisi N and Salernitano E. Anchorage of carbon nanotubes grown on carbon fibres. Carbon. 2006; 44:671-674. http://dx.doi.org/10.1016/j. carbon.2005.09.024

22. Vilatela JJ, Deng L, Kinloch IA, Young RJ and Windle AH. Structure of and stress transfer in fibres spun from carbon nanotubes produced by chemical vapour deposition. Carbon. 2009; 49:4149-4158. http://dx.doi.org/10.1016/j. carbon.2011.05.045

23. Khan SU and Kim J-K. Impact and Delamination Failure of Multiscale Carbon Nanotube-Fiber Reinforced Polymer Composites: A Review. International Journal of Aeronautical Space Science. 2011; 12:115-135. http://dx.doi.org/10.5139/ IJASS.2011.12.2.115

24. Qian H, Greenhalgh ES, Shaffer MS and Bismark A. Carbon nanotube-based hierarchical composites: a review. Journal of Materials Chemistry. 2010; 20:4751-4762. http://dx.doi. org/10.1039/c000041h

25. Karapappas P, Vavouliotis A, Tsotra P, Kostopoulos V and Paipetis A. Enhanced Fracture Properties of Carbon Reinforced Composites by the Addition of Multi-Wall Carbon Nanotubes. Journal of Composite Materials. 2009; 43:977-985. http:// dx.doi.org/10.1177/0021998308097735

26. Seyhan AT, Tanoglu M and Schulte K. Mode I and mode II fracture toughness of E-glass non-crimp fabric/carbon nanotube (CNT) modified polymer based composites. Engineering Fracture Mechanics. 2008; 75:5151-5162. http://dx.doi. org/10.1016/j.engfracmech.2008.08.003

27. Garcia EJ, Wardle BL and Hart AJ. Joining prepreg composite interfaces with aligned carbon nanotubes. Composites Part A. 2008; 39:1065-1070. http://dx.doi.org/10.1016/j. compositesa.2008.03.011

28. Arai M, Matsushita K and Hirota S. Criterion for interlaminar strength of CFRP laminates toughened with carbon nanofiber interlayer. Composites Part A. 2011; 42:703-711. http://dx.doi. org/10.1016/j.compositesa.2011.01.005

29. Li Y, Horu N, Arai M, Hu N, Liu Y and Fukunaga H. Improvement of interlaminar mechanical properties of CFRP laminates using VGCF. Composites Part A. 2009; 40:2004-2012. http://dx.doi. org/10.1016/j.compositesa.2009.09.002

30. Joshi SC and Dikshit V. Enhancing interlaminar fracture characteristics of woven CFRP prepreg composites through CNT dispersion. Journal of Composite Materials. 2011; 46:665-675. http://dx.doi.org/10.1177/0021998311410472

31. Davis DC and Whelan BD. An experimental study of interlaminar shear fracture toughness of a nanotube reinforced composite. Composites Part B. 2011; 42:105-116. http://dx.doi. org/10.1016/j.compositesb.2010.06.001

32. Garcia EJ, Wardle BL, Hart AJ and Yamamoto N. Fabrication and multifunctional properties of a hybrid laminate with aligned carbon nanotubes grown In Situ. Composites Science and Technology. 2008; 68:2034-2041. http://dx.doi.org/10.1016/j. compscitech.2008.02.028

33. Mathur A, Wadhwa S, Tweedie M, Hazra KS, Dickinson C, Roy SS et al. A comparative study of the growth, microstructural and electrical properties of multiwall CNTs grown by thermal and microwave plasma enhanced CVD methods. Physica E. 2011; 44:29-36. http://dx.doi.org/10.1016/j. physe.2011.06.035

34. Koo JH, Loa SC, Lee J, Chen DZ, Lam C, Yong W et al. Morphology and thermal characterization of nanographene platelets. Journal of Materials Science. 2011; 46:3583-3589. http://dx.doi.org/10.1007/s10853-011-5272-7 
35. Dresselhaus MS, Dresselhaus G, Saito R and Jorio A. Raman spectroscopy of carbon nanotubes. Physics Report. 2005; 409:47-99. http://dx.doi.org/10.1016/j. physrep.2004.10.006

36. American Society for Testing and Materials. ASTM D 3039 Standard. ASTM Year Book of Standards. 2011; 8.03:1-19.
37. Malard LM, Pimenta MA, Dresselhaus G and Dresselhaus MS. Raman spectroscopy in graphene. Physics Reports. 2009; 473:51-87. http://dx.doi.org/10.1016/j.physrep.2009.02.003

38. Thostenson ET, Li C and Chou T-W. Nanocomposites in context. Composites Science and Technology. 2005; 65:491-516. http:// dx.doi.org/10.1016/j.compscitech.2004.11.003 